\title{
The effect of Khat (Catha edulis) chewing on blood pressure among male adult Chewers, Bahir Dar, North west Ethiopia
}

\author{
Bizuayehu Walle Birhane*, Muluken Walle Birhane \\ Medical physiology, College of Medicine and Health Science, Bahir Dar University, Bahir Dar, Ethiopia \\ Email address: \\ rebalebeta@gmail.com (B. Walle Birhane),ninawalle@yahoo.com (M. Walle Birhane)
}

To cite this article:

Bizuayehu Walle Birhane, Muluken Walle Birhane. The Effect of Khat (Catha edulis) Chewing on Blood Pressure among Male Adult Chewers, Bahir Dar, North West Ethiopia. Science Journal of Public Health. Vol. 2, No. 5, 2014, pp. 461-468.

doi: $10.11648 /$ j.sjph.20140205.23

\begin{abstract}
Khat is found in the evergreen tree or large shrub, consists of whole fresh leaves and buds of a plant known as Catha edulis. Bahir Dar is a city that three percent of Ethiopia's total production of khat is originated from. There is no community based study that has been done in Bahir Dar city to determine effects of khat chewing behaviours on risk to elevated blood pressure. Therefore, this study aimed to assess effect of khat chewing on systolic and diastolic blood pressure. A community based cross-sectional study was conducted from January to September 2013among chewers of Bahir Dar city for determine effect of khat chewing on systolic and diastolic blood pressure. A structured questioner and medical measuring equipments were used to collect socio-demographic data, khat chewing behaviours and levels of physiological parameters. A total of 422 male khat chewers were included in study, 422 respond to the questioners, giving a response rate of $100 \%$. The multivariate analysis result shown that the figure of having elevated systolic blood pressure among male chewers who chewed frequently was fourteen times more compared to who chewed less frequently (AOR:14.95,95\%CI:5.49-40.66). The analysis result also revealed that those who spent more than 6 hours in a khat session were 7.25 times more likely to have elevated systolic blood pressure compared to those who spent less than 6 hours, (AOR :7.25; 95\%CI: 4.03-13.05). It was also found that those who spent more than 6 hours in a khat session were almost 9 times more likely to have elevated diastolic blood pressure compared to those who spent less than 6 hours (AOR:8.99,95\%CI:4.85-16.66). As for amount of khat chewed in the last 12 months, the risk of elevated systolic blood pressure was more than 5.26 times more likely among male chewers who reported increase amount of khat chewing compared to those who reported decrease the amount in the last 12 months, (AOR:5.26:95\% CI: 2.76-10.15). Similarly, the risk of elevated diastolic blood pressure was more than 7 times more likely among male chewers who reported increase amount of khat chewing compared to those who reported decrease amount of khat chewing in last 12 months (AOR:7.25,95\%CI:3.66-14.38). According to the study result explained above, it is possible to conclude that khat chewing behaviours have significant effect on blood pressure.
\end{abstract}

Keywords: Khat Chewing, Health Outcomes, Bahir Dar, North West Ethiopia

\section{Introduction}

Khat (Catha edulis), found in the evergreen tree or large shrub of Celastracea family, that consists of whole fresh leaves and buds of a plant, and it is indigenous to Ethiopia, Kenya, and Yemen [1]. Now a day, Catha edulis is widely cultivated in all parts of the country and neighboring regions like Somalia, Malawi, Uganda, Tanzania, Congo, Zambia, Zimbabwe, Afghanistan and Madagascar [2]. Khat is consumed regularly with the young generations [3, 4].
The total area of land under khat cultivation in Ethiopia of the year 1997/98 was estimated at 78,570 hectare [5]. Oromia, mainly East and West Hararghe zones, is the most important centre of khat production and is considered to be the leading producer of quality khat in the world and Bahir Dar, the capital city of Amahara regional state is the place that three percent of Ethiopia's total production of khat is originated from [6].

Catha edulis contains more than 20 different compounds including: alkaloids of the phenylpropylamine type of 
which the main psychoactive constituent is $\mathrm{S}-(-)-\alpha-$ aminopropiophenone (cathinone) [7,8], together with the less psychoactive phenylpropanolamine diastereomers S,S-(+)- norpseudoephedrine (cathine) and R,S-(-)-norephedrine [9-11]. Catha edulis also contains tannins ( $7-14 \%$ by weight in dried leaves) and minute amounts of thiamine, niacin, riboflavin, iron and amino acids [12]. Cathinone, which is the main active ingredient in Khat leaves, is responsible for the pharmacological properties of Khat [13-15]. This active ingredient affects the central and peripheral nervous system [16, 17]. Catha edulis also leads to several effects that include the development of a dry mouth, blurred vision and mydriasis [18] and it also affects the cardiovascular activities [19]. These effects are believed to result from the ability of cathinone (like amphetamine) to act as an indirect sympthomimetic agent and to facilitate the release of catecholamines from sympathetic nerve terminals [20,21]. Chronic use of Catha edulis has also been associated with the increased incidence of acute coronary vasospasm and myocardial infarction [22]. A direct vasoconstrictor action of (-)-S-cathinone has been demonstrated, in which it produced a dose-dependent vasoconstriction in both Langendorffperfused guinea-pig hearts and isolated aortic rings [22]. Studies show that khat chewing delays gastric emptying of a semi-solid meal, probably as a result of the sympathomimetic action of cathinone in khat [23]. A common complaint of khat chewers is constipation, probably caused by a combination of the astringent properties of the chemical in khat, called tannins and the sympathomimetic properties of cathinone [24].

During khat sessions, the leaves and the bark of the plant are chewed slowly over several hours and the juice of the masticated leaves is swallowed but not the residues [25]. Most men chew Catha edulis leaves for several hours per day to enjoy the taste and to experience the stimulating effect on the nervous system [26].

The use of Khat is an established cultural tradition for many social situations in the areas of primary cultivation, East Africa and the Arabian Peninsula and several million people may be chewing Khat worldwide, with an estimated 10 million people chewing Khat leaf daily [27]. Various reasons have been given for chewing Khat from place to place. Most chewers used Khat to gain good level of concentration for praying [28]. Some chewers reported that Khat intake results in increased energy levels and alertness, enhances imaginative ability and the capacity to associate ideas, and improves the ability to communicate [28-29]. Studies on the effect of substance abuse and their health effects are scarce despite the ever-growing rate of substance use behaviors [30].

In Ethiopia khat is used for direct consumption, local sale and for export. It is estimated that 85 to $90 \%$ of khat production is for sell; the rest is used for local consumption [31]. The habit of khat chewing is believed to affect a large segment of the Ethiopian population, especially the productive age group [32].
The amount and frequency of chewing are behaviours that strongly affect the magnitudes of the effect of khat chewing on human beings and the description of khat chewing frequency in the literature is varied. For example; one study [33] reported current habitual khat chewing as 'daily', and more frequently as 'occasional'. Another study also [34] reported khat chewing as once a week or less as 'occasional', 2-3 days as 'light', 4-6 days per week as 'frequent' and every day as 'heavy'. World Bank survey study result in Yemen [35] reported that khat chewing three and more days per week as 'addictive'. A study also [36] defined the pattern of khat chewing every day as 'regular' and other patterns as once a week 'occasional'.

\section{Methods and Materials}

This study was conducted in Bahir Dar town, North West Ethiopia, from January to September 2013, using a cross-sectional design. The source population of this study was all Bahir Dar town male khat chewers and the study population was sampled khat chewers of the town. Systematic random sampling technique was employed to select samples of khat sellers and cluster sampling technique was used to select study participants.

The sample size (n) was calculated by considering $95 \%$ confidence level, $\mathrm{p}=0.5$, margin error $(\mathrm{d})=5 \%(0.05)$ and the estimated sample size of the study was 422. All voluntary khat chewers in the sampled khat sellers were included in the study.

The sample for this study was drawn from places of khat sales and systematic procedures were carried out to select the eligible khat chewers for the study, the procedures included; identifying the kebeles/villages which sellers were highly populated, identifying or recruitment of khat sellers from a given kebele/village and selection of khat chewers from the recruited khat sellers. Sampling was conducted through sellers to sellers survey in which, every second khat sellers was selected through systematic random sampling and all khat chewers in selected sellers were included as the study participants. All volunteers in the sampled sellers were included in the study.

For data collection, a pretested questionnaire pertinent to the study objectives were developed and used. The questionnaire was translated into Amharic and distributed to all sampled khat chewers. Medical equipments and materials such as sphygmomanometer with stethoscope, digital thermometer and others were used to measure the level of physiological parameters. Four trained nurses were involved in data collection, and supervision was carried out by the principal investigator.

Data entry, clearing and analysis were made using SPSS. To assess the effects of khat chewing

Khat chewing behaviours (amount and frequency of chewing) on blood pressure, p-value, chi-square test, adjusted odds ratio (AOR) and confidence interval $(95 \% \mathrm{CI})$ were considered. Bivariate and multivariate logistic regression analyses were made to determine the 
statistically significant effects of khat chewing behaviours on blood pressure.

Ethical clearance and permission were first obtained from the Ethical Review Boards of Bahir Dar University. The study participants were informed about the objective of the study and asked their consent to be involved in the study.

Confidentiality was also maintained.

The following operational definitions were used in this study:

Grams of khat: the amount of khat leafs sold to chewers in the study area during khat session.

Frequent chewers: those who chew khat for three and more days a week.

Less frequent khat chewers: those who chew khat less than three days a week.

Physiological parameters: are those that specify the work of heart and respiratory system.

Levels of physiological parameters: physiology books state the level of physiological parameters for adult male person as follows; systolic and diastolic pressure is 120 and $80 \mathrm{mmHg}$ respectively; breathing rate: $12-16 \mathrm{breath} /$ minute; body temperature: $37^{\circ} \mathrm{C}$; body mass index: $<18 \mathrm{~kg} / \mathrm{m} 2$ under weight, $18-25 \mathrm{~kg} / \mathrm{m} 2$ normal and26-30 kg/m2 overweight; heart rate: $60-100$ beat/minute.

Self rated health status: is a reliable and valid way of diagnosing patients when compared with physician-reported medical histories.

Khat sellers: those who earning money from chewers by prepared a special place and setup for chewers and sold grams of khat for chewers during khat session.

Khat chewing behaviours: frequency of khat chewing per week, time of the day that spent during khat session, amount of khat chewed within the last 12 months, and grams of khat chewed during khat session.

\section{Results}

\subsection{Socio Demographic Characteristics}

A total of 422 male khat chewers were included in this study, 422 of them were responded to the questioners, giving a response rate of $100 \%$. The study found that the mean age of participants with standard deviation was $30.31 \pm 1.39$ years old. More than half of the male chewers (58.1) were in age between 30-40 years old. Majority (71.6\%) of participants were born in Bahir Dar city. Regarding educational status, 160(37.9\%) 65 (15.4\%) and $158(37.4 \%)$ participants had completed high school, college diploma and university degree and above respectively. Out of the total male khat chewers, $59.2 \%$ were unemployed. With regard to marital status more than half of male khat chewers $(62.8 \%)$ were single. Three hundred thirty $(78.2 \%)$ of participant had no children (Table 1).
Table 1. Socio-demographic characteristics among male khat chewers in Bahir Dar city, 2013.

\begin{tabular}{|c|c|c|}
\hline Variable & Frequency $(\mathbf{N})$ & Percentage (\%) \\
\hline \multicolumn{3}{|l|}{ Age in years } \\
\hline $18-29$ & 187 & 44.3 \\
\hline $30-40$ & 201 & 47.6 \\
\hline $41-64$ & 34 & 8.1 \\
\hline \multicolumn{3}{|l|}{ Place of birth } \\
\hline Bahir Dar & 302 & 71.6 \\
\hline Outside Bahir Dar & 120 & 28.4 \\
\hline \multicolumn{3}{|l|}{ Educational status } \\
\hline Illiterate & 10 & 2.4 \\
\hline Primary school & 29 & 6.9 \\
\hline Higher School & 160 & 37.9 \\
\hline College diploma & 65 & 15.4 \\
\hline University degree and above & 158 & 37.4 \\
\hline \multicolumn{3}{|l|}{ Job title } \\
\hline Employed & 172 & 40.8 \\
\hline Unemployed & 250 & 59.2 \\
\hline \multicolumn{3}{|l|}{ Marital status } \\
\hline Married & 141 & 33.4 \\
\hline Single & 265 & 62.8 \\
\hline Divorced & 14 & 3.3 \\
\hline Widowed & 2 & 0.5 \\
\hline \multicolumn{3}{|l|}{ Number of children } \\
\hline None & 330 & 78.2 \\
\hline One & 42 & 10.0 \\
\hline Two & 28 & 6.6 \\
\hline Three & 10 & 2.4 \\
\hline More than 3 & 12 & 2.8 \\
\hline
\end{tabular}

\subsection{Khat Chewing Behavior among Chewers}

This section describes the social and behavioral backgrounds of khat chewing, frequency of khat chewing, amount of khat chewing, any attempts to stop khat chewing, the reasons for re-starting chewing, education/information on khat impacts and a validation of self-reported khat chewing.

In this study found that thirty seven percent (37.2\%) of the participants had already started khat chewing at the age of between 19 to 21 years old. Majority of the respondents $(80.6 \%)$ started khat chewing in Bahir Dar. Around 326 $(77.3 \%)$ of them were initiated chewing for the first time by their own close friends. Many reasons were reported for khat chewing; most commonly help pass time (29.4\%) and dependence $(24.2 \%)$. Family khat chewing history was also explored; Thirty eight percent and $1.9 \%$ of participants' fathers and mothers were khat chewers. Fifty four percent of participant chewed khat in groups (with friends). Most 375 (88.9\%) of participants reported chewing khat for three days or more and only $3.6 \%$ chewed less than three days per week. With regarding to the amount of money costed during khat chewing, $36 \%$ of khat chewers were coasted 101 Ethiopian birr and more during a khat session. The most commonly reported time for starting khat chewing was between 1.00 pm - 3.00 pm while a small percentage (3.6\%) preferred between 4 pm- 6 pm. Thrifty eight percent of the participants reported chewing 100 and more grams of khat per day during khat session. Fifty four percent of chewers had spent greater than or equal to six hours during a khat session.

Different aspects of khat chewing behaviours, including 
frequency and amount were also assessed. Out of the total participants, majority $(64.0 \%)$ of them were reported increases their khat chewing desire in the last 12 months while smallest percentage (10.4\%) of participants decreases their desire (Table 2)

Table 2. Social and behavioral background of khat chewing among male khat chewers in Bahir Dar city, 2013.

\begin{tabular}{|c|c|c|}
\hline Variable & $\begin{array}{l}\text { Frequency } \\
\text { (N) }\end{array}$ & $\begin{array}{l}\text { Percentage } \\
(\%)\end{array}$ \\
\hline \multicolumn{3}{|l|}{ Age of starting khat chewing } \\
\hline From $7-15$ years & 56 & 13.3 \\
\hline From $16-18$ years & 106 & 25.1 \\
\hline From $19-21$ years & 157 & 37.2 \\
\hline 22 years to older & 103 & 24.4 \\
\hline \multicolumn{3}{|l|}{ Initiators of khat chewing } \\
\hline Close friends & 326 & 77.3 \\
\hline Family & 24 & 5.7 \\
\hline By yourself & 72 & 17.1 \\
\hline \multicolumn{3}{|l|}{ Reasons for chewing khat } \\
\hline A habit & 83 & 19.7 \\
\hline Need Social interaction & 77 & 18.2 \\
\hline Help pass the time & 124 & 29.4 \\
\hline Dependence & 102 & 24.2 \\
\hline $\begin{array}{l}\text { Increase concentration during study } \\
\text { and work }\end{array}$ & 28 & 6.6 \\
\hline \multicolumn{3}{|l|}{ Khat chewing setting } \\
\hline Alone & 6 & 1.4 \\
\hline With others & 228 & 54.0 \\
\hline sometimes with others sometimes alone & 188 & 44.5 \\
\hline \multicolumn{3}{|c|}{ Number of Days Chewing khat per Week } \\
\hline$<3$ days & 47 & 11.1 \\
\hline$\geq 3$ days & 375 & 88.9 \\
\hline \multicolumn{3}{|c|}{ Amount of money (in birr) coasted for a khat session } \\
\hline From lowest up to 50 birr & 135 & 32.0 \\
\hline $51-100$ birr & 135 & 32.0 \\
\hline From 101 birr to above & 152 & 36.0 \\
\hline \multicolumn{3}{|l|}{ Time Preferred for Starting Chewing } \\
\hline 4-6 local time & 73 & 17.3 \\
\hline 7-9 local time & 334 & 79.1 \\
\hline 10-12 local time & 15 & 3.6 \\
\hline \multicolumn{3}{|l|}{ Amount of khat chewed } \\
\hline $25 \mathrm{gm}-50 \mathrm{gm}$ & 118 & 28.0 \\
\hline $51 \mathrm{gm}-100 \mathrm{gm}$ & 143 & 33.9 \\
\hline$>=100 \mathrm{gm}$ & 161 & 38.2 \\
\hline \multicolumn{3}{|l|}{ Time period spend during a Khat Session } \\
\hline Up to 6 hours & 192 & 45.5 \\
\hline More than or equal to 6 hours & 230 & 54.5 \\
\hline
\end{tabular}

\subsection{Health Outcomes and Related Behaviors}

Almost all (96.7\%) study participants had no history of illness. Amongst the participant who self reported illness history, $50 \%$ of them reported GI conditions (Gastritis) and $21.4 \%, 14.3 \%, 14 \%$ reported hypertension, diabetics and hemorrhoid respectively. With regard to self rated health condition, twenty four percent of participants self-rated very good and good health and sixty six percent rated fair, bad and very bad respectively.

Sixty two percent of participants reported oral health problems. Of the 262, self-reported oral problems, $78.6 \%$ had dental decay or tooth discoloration, $21.4 \%$ gum problems (inflammation, bleeding).
Table 3. Self rated health outcomes among male khat chewers in Bahir Dar city, 2014.

\begin{tabular}{lll}
\hline Variables & Frequency(N) & Percentage (\%) \\
\hline Illness history & & \\
Yes & 14 & 3.3 \\
No & 408 & 96.7 \\
Self-rated health status & \\
Very good & 71 & 16.8 \\
Good & 30 & 7.1 \\
Fair & 133 & 31.5 \\
Bad & 92 & 21.8 \\
V. bad & 96 & 22.7 \\
Oral and dental health problem & \\
Tooth decay & 206 & 48.8 \\
Gum bleeding & 56 & 13.3 \\
No problem on both & 160 & 37.9 \\
Visit dentist before & & \\
yes & 14 & 3.3 \\
No & 408 & 96.7 \\
\hline
\end{tabular}

\subsection{The Levels of Physiologic Parameters}

Out of the total respondents, majority, $85.3 \%$ and $67.1 \%$ of the participant were their systolic and diastolic blood pressure greater than 120 and $80 \mathrm{mmHg}$ respectively.

Table 4. Levels of physiological parameters among male khat chewers, Bahir Dar City, 2013

\begin{tabular}{lll}
\hline Variable & Frequency $(\mathbf{N})$ & Percentage (\%) \\
\hline $\mathrm{SBP}(\mathrm{mmHg})$ & & \\
$<120$ & 142 & 33.6 \\
$\geq 120$ & 280 & 66.4 \\
$\mathrm{DBP}(\mathrm{mmHg})$ & & \\
$<80$ & 139 & 32.9 \\
$\geq 80$ & 283 & 67.1 \\
$\mathrm{PP}(\mathrm{mmHg})$ & & \\
$<40 \mathrm{mmHg}$ & 21 & 5.0 \\
$\geq 40 \mathrm{mmHg}$ & 401 & 95 \\
Respiratory rate & & \\
$12-15$ breath/minute & 64 & 15.2 \\
$>15$ breath/minute & 358 & 84.8 \\
Heart rate & & \\
$60-100$ beat $/$ min & 340 & 80.6 \\
$>100$ beat $/$ minute & 82 & 19.4 \\
Temperature $\left({ }^{\circ} \mathrm{c}\right)$ & & \\
$<37$ & 416 & 98.6 \\
$\geq 37$ & 6 & 1.4 \\
Body mass index $(\mathrm{kg} / \mathrm{m} 2)$ & & 72.5 \\
$<18$ & 306 & \\
$18-25$ & & \\
$26-30$ & & \\
\hline
\end{tabular}

\subsection{Factors Associated with Systolic Blood Pressure}

The multivariate analysis result (Table-5) indicated that frequency of khat chewing, time period spend during a khat session, amount of khat chewing for the last 12 month and difficulty to stop/ go without khat chewing were statistically significantly affected the level of systolic blood pressure. The multivariate analysis result revealed that the figure of 
having elevated systolic blood pressure among male chewers who chewed frequently was fourteen times more compared to who chewed less frequently (AOR:14.95,95\%CI:5.49-40.66). Time period spend during a khat session and level of khat chewing in the last 12 months also have statistically significant effect on systolic blood pressure, the findings shown that, those who spent more than 6 hours in a khat session were 7.24 times more likely to have elevated systolic blood pressure compared to those who spent less than 6 hours, (AOR :7.24; 95\%CI: 4.03-13.05). The risk of elevated systolic blood pressure was more than 5.26 times more likely among male chewers who reported increase amount of khat chewing compared to who reported decrease amount of khat chewing in last 12 months, (AOR:5.26:95\% CI: 2.76-10.15). With regard to difficulty to addictive behaviors of khat chewing; those male chewers who reported impossible and very difficult to stop or go without khat chewing 3.83 and 9.91times more likely to have elevated blood pressure compared to those male chewers who reported not difficult to stop or go without khat (AOR: 3.83, 95\%CI: 1.87-7.88) and (AOR: 9.91, 95\%CI: 4.70-20.88) respectively.

Table 5. Factors associated with systolic blood pressure among male khat chewers, in Bahir Dar city, 2013.

\begin{tabular}{|c|c|c|c|c|c|}
\hline \multirow{2}{*}{ Variable } & \multicolumn{2}{|l|}{ SBP } & \multirow[t]{2}{*}{$\operatorname{COR}(95 \% \mathrm{CI})$} & \multirow[t]{2}{*}{$\operatorname{AOR}(95 \% C I)$} & \multirow[t]{2}{*}{ P-value } \\
\hline & $\geq 120 \mathrm{mmHg}$ & $<120 \mathrm{mmHg}$ & & & \\
\hline \multicolumn{6}{|l|}{ Frequency of khat chewing } \\
\hline$<3$ days & 12 & 35 & 1.00 & 1.00 & \multirow{2}{*}{0.001} \\
\hline$\geq 3$ days & 268 & 107 & $7.31(3.65-14.61)$ & $14.95(5.49-40.66)$ & \\
\hline \multicolumn{6}{|c|}{ Time period spend during a khat session } \\
\hline Up to 6 hours & 78 & 114 & 1.00 & 1.00 & \multirow{2}{*}{0.001} \\
\hline More than or equal to 6 hours & 202 & 28 & $10.54(6.47-17.19)$ & $7.25(4.03-13.05)$ & \\
\hline \multicolumn{6}{|c|}{ Amount of khat chewing the last 12 month } \\
\hline Increase & 218 & 52 & $5.52(2.83-10.77)$ & $5.29(2.76-10.15)$ & \multirow{3}{*}{0.001} \\
\hline Remain the same & 43 & 65 & $0.87(0.43-1.77)$ & $0.98(0.40-2.39)$ & \\
\hline Decrease & 19 & 25 & 1.00 & 1.00 & \\
\hline \multicolumn{6}{|c|}{ Difficult to stop or go without khat chewing } \\
\hline Not difficult & 76 & 102 & 1.00 & 1.00 & \multirow{3}{*}{0.001} \\
\hline Very difficult & 57 & 23 & $3.29(1.87-5.81)$ & $3.83(1.87-7.88)$ & \\
\hline Impossible & 147 & 18 & $10.85(6.12-19.25)$ & $9.91(4.70-20.88)$ & \\
\hline
\end{tabular}

\subsection{Factors Associated with Diastolic Blood Pressure}

The multivariate analysis result, revealed that having elevated diastolic blood pressure among male chewers who chewed frequently was five times more compared to who chewed less frequently (AOR:5.43.95\%CI:2.05-14.38). It was also found that those who spent more than 6 hours in a khat session were almost 9 times more likely to have elevated diastolic blood pressure compared to who spent less than 6 hours (AOR:8.99,95\%CI:4.85-16.66). The risk of elevated diastolic blood pressure was more than 7 times more likely among male chewers who reported increase amount of khat chewing compared to who reported decrease amount of khat chewing in last 12 months (AOR:7.25,95\%CI:3.66-14.38). With regard to addictive behaviors of khat chewing; those male chewers who reported impossible and very difficult to stop or go without khat chewing 3.43 and 14.74 times more likely to have elevated diastolic blood pressure compared to those male chewers who reported not difficult to stop or go without khat (AOR: 3.43, 95\%CI: 1.67-7.03) and (AOR: 14.74, 95\%CI: 6.61-32.85) respectively. (Table 6)

Table 6. Factors associated with diastolic blood pressure among male khat chewers, in Bahir Dar city, 2013.

\begin{tabular}{|c|c|c|c|c|c|}
\hline \multirow{2}{*}{ Variable } & \multicolumn{2}{|l|}{ DBP } & \multirow{2}{*}{$\operatorname{COR}(95 \% \mathrm{CI})$} & \multirow{2}{*}{$\operatorname{AOR}(95 \% C I)$} & \multirow{2}{*}{ P-value } \\
\hline & $\geq 80 \mathrm{mmHg}$ & $<80 \mathrm{mmHg}$ & & & \\
\hline \multicolumn{6}{|c|}{ Frequency of khat chewing } \\
\hline$<3$ days & 18 & 29 & 1.00 & 1.00 & \multirow{2}{*}{$0.01 *$} \\
\hline$\geq 3$ days & 265 & 110 & $3.88(2.07-7.28)$ & $5.43(2.05-14.38)$ & \\
\hline \multicolumn{6}{|c|}{ Time period spend during a Khat Session } \\
\hline Up to 6 hours & 77 & 115 & 1.00 & 1.00 & \multirow{2}{*}{$0.001 *$} \\
\hline$\geq 6$ hours & 206 & 24 & $12.82(7.68-21.38)$ & $8.99(4.85-16.66)$ & \\
\hline \multicolumn{6}{|c|}{ Amount of khat chewing the last 12 month } \\
\hline Increase & 223 & 47 & $6.24(3.18-12.25)$ & $7.25(3.66-14.38)$ & \multirow{3}{*}{$0.001 *$} \\
\hline Remain the same & 41 & 67 & $.805(.39-1.64)$ & $1.13(0.45-2.84$ & \\
\hline Decrease & 19 & 25 & 1.00 & 1.00 & \\
\hline \multicolumn{6}{|c|}{ Adictive behaviors of khat chewing } \\
\hline Not difficult & 75 & 102 & 1.000 & 1.00 & \multirow{3}{*}{$0.001 *$} \\
\hline Very difficult & 55 & 25 & $2.99(1.71-5.23)$ & $3.43(1.67-7.03)$ & \\
\hline Impossible & 153 & 12 & $17.34(8.97-33.51)$ & $14.74(6.61-32.85)$ & \\
\hline
\end{tabular}




\section{Discussion}

Studies on substance abuse and their effects on health are scarce despite the ever-growing rate of substance use behaviours. Previous studies shown that, khat chewing had effects on the physical wellbeing of the society; therefore this study aims to investigate the effects of khat chewing behaviors on blood pressure. The mean age of participants with standard deviation of this study was $30.31+1.39$ years old.

According to this study $37.9 \%, 15.4 \%$ and $37.4 \%$ of khat chewers were completed a high school, college diploma and university degree and above respectively this is higher than study conducted in Jimma which was $8.5 \%$ of the respondents were completed the high school and higher education programs.

The habit of khat chewing is more frequently in the age group between 16 and 21 years and less common above the age of 41. This is supported by study conducted in UK-resident Male Yemeni Khat chewers indicated that majority of khat chewers' age were in the productive age groups and more than half of the respondents were started chewing at the age of $18[37,39]$

The probable difference might be due the presence of certain behavioral, lifestyle and personality variation.

The present study showed that, majorities (77.3\%) of chewers were initiated khat chewing for the first time by their own close friends, and their reason for khat chewing most commonly was for helping pass time and dependency. This study is in line with the study in Jimma University students reported that, khat chewing initiated for the first time by friends and family [36].

This study result showed that $38.2 \%$ of the respondents reported chewing 100 and more grams of khat per day during a khat session. $54.5 \%$ of chewers had spent six and more hours during a khat session and around $64 \%$ of the participants were reported increases the amount and their desire for khat chewing in the last 12 months. This may due to lack of job opportunities in the city and absence of concerned bodies that tried to band khat chewing in the country.

In this study, $62.1 \%$ of participants reported oral health problem, $78.6 \%$ had dental decay or tooth discoloration and $22.4 \%$ gum problem (inflammation, bleeding). Similar study conducted in Yemen [23] reported that khat chewers were often complained inflammation of the mouth. These effects may be due to the presence of harsher chemical called tannins in khat and using sugar during khat session to minimize the bitterness of khat juice [40, 41]

Previous study that was conducted in Yemen reported that khat chewing produced a significant rise in arterial systolic and diastolic blood pressure [42]. In the present study, there is also the risk of having elevated systolic blood pressure among frequent khat chewers aroun14 times more compared to less frequent chewers (AOR: 14, 95\%CI: 5.49-40.66).

Those chewers who spent more time on khat chewing during khat session were 7.24 times more likely to have elevated systolic blood pressure compared to chewers who spent less time (AOR: 7.24, 95\% CI: 4.03-13.05).

The risk of elevated systolic blood pressure was also more than 5.26 times more likely among chewers who reportedly increases the amount of khat chewing for the last 12 months (AOR: 5.26, 95\%: 2.76-10.15).

As for difficulty to stop or go without khat chewing, chewers who respond impossible and very difficult to stop or go without khat chewing were 3.83 and 9.91 times more likely to have elevated systolic blood pressure compared to those who reported not difficult to stop or go without khat.

The diastolic blood pressure is also significantly associated with that of the above chewing habits that affected the systolic blood pressure.

According to this study result, amount, frequency and chronic khat chewing was statistically significantly associated with that of the risk of elevation of arterial blood pressure. This may be due to the result of sympathetic like action of an active ingredient of khat known as cathinone [43].

\section{Conclusion}

This work and previous studies demonstrated that khat intake causes risks on cardiovascular problems such as hypertension and oral health problem. In addition to the cardiovascular effect, khat has influence on the respiratory center, which is expressed as quick breathing, marked hyperthermia and finally death.

Chronic khat chewing also produces direct effect on the gastrointestinal system resulting in such disorders as osophagitis, stomatitis, gastritis, gastric and duodenal ulcer, entercolitis, hepatitis, and pancreatitis.

Currently, the habit of khat chewing affects a large segment of the population, especially the productive age group and its negative impact on health; socioeconomic and political matters are reported enormously by study findings. This is because the habit of khat chewing reinforces the development of other habits such as cigarette smoking, alcohol intake and addiction with narcotics.

This study has strengths and weaknesses. As strength, authentic data were intensively collected from study populations by convincing the sampled khat sellers and scientific medical equipments were used to measure physiological parameters, systolic and diastolic blood pressure. There is no study conducted here in Bahir Dar about effects of khat chewing on blood pressure and this study may give preliminary information about khat chewing habits and its effect on cardiovascular system and this study may give a clear direction for anyone who wants to conduct further investigation on the effects of abused drugs on human physiology in general and on cardiovascular system in particular. As a limitation, it was better if the study covers many areas of the country and incorporates large sample sizes for better inference. However, due to the limitations of resources, this study was focused only on Bahir Dar city. 


\section{Recommendation}

To sum up, using this as a preliminary study, further investigation should be continued to explain exhaustively to determine the effect of chronic khat chewing on the mental health and detailed experimental work on the cardiovascular effect of khat. Khat chewing is also suspected to be the risk factor of peptic ulcer disease. This again needs careful observation. Health education about the adverse effect of khat chewing should be delivered to the community and health institutions. Based on this recommendation, policy makers should design strategies to control the production, usage and distribution of khat in Ethiopia.

\section{Abbreviations}

$\begin{array}{ll}\text { ABP } & \text { Arterial Blood Pressure, } \\ \text { SBP } & \text { systolic blood pressure } \\ \text { DBP } & \text { diastolic blood pressure } \\ \text { PP } & \text { pulse pressure } \\ \text { AOR } & \text { Adjusted Odds ratio, } \\ \text { CI } & \text { Confidence Interval; } \\ \text { COR } & \text { Crude Odds Ratio; } \\ \mathrm{UK} & \text { United Kingdom } \\ \mathrm{kg} / \mathrm{m} 2 & \text { kilogram per meter square } \\ \mathrm{mmHg} & \text { millimeter mercury }\end{array}$

\section{Competing Interests}

The authors declare that they have no competing interests.

\section{Authors' Contributions}

Bizuayehu Walle designed the study, conducted field work, analyzed data, interpreted findings, and wrote the manuscript. Muluken Walle and Kidest Reba involved in the design, development of the proposal, assisted field work, in data analysis and manuscript writing. All authors of the manuscript have read and agreed to its content.

\section{Acknowledgement}

I would like to thank the Research and Publication Office of the Bahir Dar university college of medicine and health science for funding this study. I also thank Mr. Bekele (MSc. in general public health) for carefully revising this manuscript and forwarding constructive and timely comments for the success of this work. Finally this research would not have been realized without the strong commitment of the data collectors and khat sellers.

\section{References}

[1] Al-Hebshi N, Skaug N: Khat (Catha edulis) - an updated review. Addiction Biology 2005, 10:299-307

[2] Sawair F. A., Al - Mutwakel A. Al - Eryani K. , Al - Surhy A. ,
Mar uyama S. , Cheng J ., Al - Sharabi A. , Saku T. High relative frequency of oral squamous cell carcinoma in Yemen: Qat and tobacco chewing as its aetiological back ground. International Journal of Environmental Health Research. 2 007, $17(3)$ : $185-195$.

[3] Kebede Y: Cigarette smoking and khat chewing among university instructors in Ethiopia. East Afr. Med. J. (2002) 79:274-278.

[4] Ayana Am, Sherief Ht, Tekli Y: Effect of khat (Catha edulis Forsk) on blood pressure and heart rate, a community based study. Ethiop. J. Health Dev. (2002) 16:325-334.

[5] Central Statistics Authority. 1993, Addis Ababa, Ethiopia, 1998.

[6] Peter D. Khat: its history, botany, chemistry and toxicology. Parmac. Journal CLXD: 1952, 36:39

[7] Szendrei K: The chemistry of khat. Bull. Narc. (1980) 32:5-35.

[8] Kalix P: Cathinone, a natural amphetamine. Pharmacol. Toxicol. (1992) 70:77-86.

[9] Schorno X, Steinegger E: CNS-active phenylpropylamines of Catha edulis Forsk (Celastraceae) of Kenyan origin. Experintia (1979) 35:572-574.

[10] Brenneisen R, Geisshusler S: Psychotropic drugs. Part III. Analytical and chemical aspects of Catha edulis Forsk Pharm. Acta Helv. (1985) 60:290-301.

[11] Schechter MD: Dopaminergic nature of acute cathine tolerance. Pharmacol. Biochem. Behav. (1990) 36:817-820.

[12] Lugman W, Danowski T: The use of khat in Yemen: social and medical observations. Ann. Intern. Med.(1976) $85: 245-249$

[13] Patel NB: Mechanism of action of Cathinone: the active ingredient of Khat (Catha edulis). East Afr Med $J 2000$, 77:329-332.

[14] Kebede D, Alem A, Mitikie G, Enquselassie F, Berhane F, Abebe Y, Ayele R, Lemma W, Assefa T, Gebremichael T: Khat and alcohol use and risky sex behavior among in-school and out-of-school youth in Ethiopia. BMC Public Health 2005, 5:109-114.

[15] National Drug Intelligence Center, US Department of Justice: Drugs enforcement administration; Drugs and chemicals of concern "Khat". 2006 [http://www.justice.gov/dea/concern/khat.html]..

[16] Nencini P, Ahmed AM: Khat consumption: a pharmacological review. Drug Alcohol Depend. (1989) 23:19-29.

[17] Kalix P: Pharmacological properties of the stimulant khat. Pharmacol. Ther. (1990) 48:397-416.

[18] Nencini P, Abdllah A, Amiconi G, Elmi A: Tolerance develops to sympathetic effects of khat in humans. Pharmacology (1984) 28:150-154.

[19] Hassan Na, Gunaid Aa, Abdo Rabbo AA ET AL: The effect of khat chewing on blood pressure and heart rate in healthy volunteers. Trop. Doct. (2000) 30:107-108. 
[20] Kohli J, Goldberg L: Cardiovascular effect of (-)-cathinone in the anaesthetized dog: Comparison with $(+)$-amphetamine. $J$. Pharm. Pharmacol. (1982) 34:338-340.

[21] Kalix P: Effect of the alkaloid cathinone on the release of radioactivity from rabbit atria prelabelled with 3H-norepinepherine. Life Sci. (1983) 32:801-807.

[22] Al-Motarreb A, Baker K, Broadley KJ: Khat: Pharmacological and medical aspects and its social use in Yemen. Phytotherapy Res. (2002) 16:403-413.

[23] Heymann TD, Bhupulan A, Zuriekat NEK, Bomanji J, Drinkwater C, Giles P. Murray-Lyon IM. Khat chewing delays gastric emptying of a semi-solid meal. Aliment Pharmacol Ther.1995; 9: 81-83.

[24] Gunaid AA, El Khally FMY, Hassan NAGM, Murray-Lyon IM. Chewing qat leaves slows the whole gut transit time. Saudi Med Journal. 1999; 20: 444-447.

[25] Kennedy JG, Teague J, Fairbanks L: Qat use in North Yemen and the problem of addiction: a study in medical anthropology. Cult. Med. Psychiatry (1980) 4:311-344.

[26] Pantelis C, Hindler CG, Taylor JC: Use and abuse of khat (Catha edulis): a review of the distribution, pharmacology, side effects and a description of psychosis attributed to khat chewing. Psychol. Med. (1989) 19:657-668.

[27] National Drug Intelligence Center: Khat (Catha edulis): Intelligence Bulletin 2003 [http://www.justice.gov/ndic/pubs3/3920/index.htm]. No. 2003.L0424-002

[28] Alem A, Kebede D, Kullagern G: The prevalence and socio-demographic correlates of Khat chewing in Butajira, Ethiopia. Acta Psychiatrica Scand 1999, 397:84-91.

[29] Mossie A, Mekonnen Z: Khat (Catha edulis Forsk) chewing, sociodemographic description and its effect on academic performance, Jimma University students. Ethiop Med J 2004, 42:125-143.

[30] Ibrahim MM: Future of research in hypertension in developing countries. Eastern Mediterranean Health Journal 1996, 2:202-205.

[31] Dechassa, L. Khat (Catha edulis): Botany, Distribution, Cultivation, Usage and Economics in Ethiopia. UN Emergencies Unit for Ethiopia, Addis Ababa, 2001.
[32] Yigzaw Kebede, Tefera Abula, Belete Ayele, Amsalu Feleke, Getu Degu, Abera Kifle, Zeleke Alebachew, En dris Mekonnen, and Belay Tessema. Substance Abuse For the Ethiopian Health Center Team: Gonder University. 2005: 7 19

[33] Belew M, Kebede D, Kassaye M, Enquoselassie F. The magnitude of khat use and its association with health, nutrition and socio-economic status. Ethiop Med Journal, 2000, 38(1): 11-26.

[34] Numan N. Exploration of adverse psychological symptoms in Yemeni khat users by the Symptoms Checklist-90 (SCL-90). Addiction. 2004, 99(1): 61-5.

[35] World Bank. Yemen towards Qat demand reduction. 2007, 39738-YE.

[36] Ayana AM, Mekonen Z (2004). Khat (Catha edulis Forsk) chewing, socio-demographic description and its effect on academic performance, Jimma University students. Ethiop Med J. 2002. 42(2): 125-36.

[37] Belew M, Kebede D, Kassaye M, Enquoselassie F (2000). The magnitude of khat use and its association with health, nutrition and socio-economic status. Ethiop Med $J$ 38(1): 11-26.

[38] Ayana A, Sharif H, Tekli Y (2002). Effects of khat (Catha edulis forsk) on blood pressure and heart rate, a community based study. Ethiopian Journal Development 16(3): 325-334

[39] Kassim S(2010). An Exploration of the Association between Khat Chewing and Health Outcomes in UK-resident Male Yemeni Khat Chewers,22-62

[40] Fekade A, Challi J, Tadess M. Khat chewing among Agaro secondary school students. Ethiop Medic J. 1994;32:161166.

[41] Kalman S. Recent progress in khat chemistry: in chemical and pharmacological aspect of khat; international symposium of khat. 1983;13- 28 .

[42] Al-Motarreb AL, Al-Kebsi M, Al-Adhi B, Broadley KJ. Khat chewing and acute myocardial infarction. Heart. 2002; 87: 279-280.

[43] Wilder P, Mathys K, Brenneisen R, Kalix P, Fisch HU. Pharmacodynamics and pharmacokinetics of khat: a controlled study. Clin Pharmacol Ther. 1994; 59:556- 562. 